Revista Universo Contábil, ISSN 1809-3337

FURB, v. 5, n.4, p. 94-115, out./dez., 2009

doi:10.4270/ruc.2009433

Disponível em www.furb.br/universocontabil

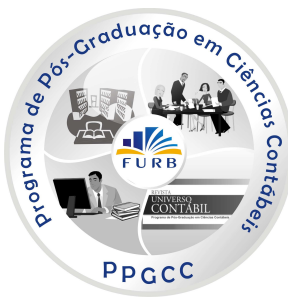

FACTORES DETERMINANTES NA IMPLEMENTAÇÃO DO BALANCED SCORECARD EM PORTUGAL*

\title{
FATORES DETERMINANTES NA IMPLEMENTAÇÃO DO BALANCED SCORECARD EM PORTUGAL
}

\section{DETERMINING FACTORS OF THE BSC IMPLEMENTATION IN PORTUGAL}

\author{
Patrícia Rodrigues Quesado \\ Mestre em Contabilidade e Auditoria pela Universidade do Minho \\ Professora do Instituto Politécnico do Cávado e do Ave \\ Endereço: Escola Superior de Gestão - Campus do IPCA \\ CEP: 4750-810 - Barcelos - Portugal \\ E-mail: pquesado@ipca.pt \\ Telefone: 00351253802500
}

Lucia Lima Rodrigues Doutora em Ciências Empresariais pela Universidade do Minho Professora da Universidade do Minho Endereço: Escola de Economia e Gestão - Campus de Gualtar CEP: 4710-057 - Braga - Portugal E-mail: lrodrigues@eeg.uminho.pt Telefone: 00351253604559

\section{RESUMO}

O Balanced Scorecard (BSC) é reconhecido, quer no mundo académico quer no mundo empresarial, como uma das mais poderosas ferramentas de Contabilidade de Gestão Estratégica. Neste sentido, desenvolvemos um estudo empírico, consubstanciado num questionário, em outubro de 2004, aplicado às 250 maiores empresas portuguesas, com o objectivo de averiguar qual o nível de conhecimento, utilização e características das empresas que adoptam este instrumento de gestão. As principais conclusões retiradas foram que apesar da maioria dos inquiridos conhecer o BSC e de o considerar mais como uma ferramenta de gestão estratégica do que como um sistema de avaliação do desempenho, a sua utilização em

Artigo recebido em 17.04.2007. Revisado por pares em 26.07.2007. Reformulado em 08.05.2008. Recomendado em 15.08.2008 por Ilse Maria Beuren (Editora). Publicado em 30.11.2009. Organização responsável pelo periódico: FURB. 
Portugal ainda é reduzida e recente. À semelhança do registado em outros países, o BSC em Portugal ainda está numa fase inicial. $\mathrm{O}$ estudo revelou também que são essencialmente as empresas pertencentes ao sector secundário que mais utilizam o BSC. Não obstante, ao contrário de outros estudos, não obtivemos evidência empírica sobre a influência de variáveis como a localização geográfica, dimensão e internacionalização na utilização e conhecimento do BSC em Portugal.

Palavras-chave: Balanced scorecard. Contabilidade de gestão. Análise empírica.

\section{RESUMO}

O Balanced Scorecard (BSC) é reconhecido, quer no mundo acadêmico quer no mundo empresarial, como uma das mais poderosas ferramentas de Contabilidade de Gestão Estratégica. Neste sentido, foi desenvolvido um estudo empírico, consubstanciado num questionário, aplicado em outubro de 2004 às 250 maiores empresas portuguesas, com o objetivo de averiguar qual o nível de conhecimento, utilização e características das empresas que adotam este instrumento de gestão. As principais conclusões foram que, apesar da maioria dos pesquisados conhecer o BSC e de considera-lo mais como uma ferramenta de gestão estratégica do que um sistema de avaliação de desempenho, a sua utilização em Portugal ainda é reduzida e recente. À semelhança do registado em outros países, o BSC em Portugal ainda está numa fase inicial de utilização. $O$ estudo revelou também que são as empresas pertencentes ao setor secundário que mais utilizam o BSC. Ao contrário de outros estudos, não foi obtida evidência empírica sobre a influência de variáveis como a localização geográfica, dimensão e internacionalização na utilização e conhecimento do BSC em Portugal.

Palavras-chave: Balanced scorecard. Contabilidade de gestão. Análise empírica.

\section{ABSTRACT}

Balanced Scorecard (BSC) is recognized, both in the academic and business world, as one of the most powerful strategic management accounting tools. Thus, a empirical study was performed, based on a questionnaire launched in October 2004 and applied to the 250 largest Portuguese companies aiming at assessing the knowledge, use, and the characteristics of companies which are adopting this management instrument. Despite the majority of the companies inquired recognizing BSC more as a strategic management tool than a performance valuation system, the results show that there is still a reduced and recent use of BSC in Portugal. Similarly to other countries, Portugal is still in the initial state of BSC utilization. Our work showed that the companies that use more BSC belong mainly to the secondary sector of industry. Nevertheless, unlike other studies, we did not get empirical evidence on the influence of variables such as geographical localization, size and internationalization, in the use and knowledge of BSC in Portugal.

Keywords: Balanced scorecard. Management accounting. Empirical analysis.

\section{INTRODUÇÃO}

Dadas as limitações dos indicadores de gestão tradicionais para avaliar o desempenho das empresas, centrados essencialmente em indicadores financeiros orientados para o curto 
prazo, torna-se necessário o desenvolvimento de modelos de indicadores de gestão que traduzam todos os factores críticos de sucesso.

O BSC é precisamente um desses modelos, que procura favorecer a implementação da estratégia através da definição e seguimento de um conjunto de indicadores coerentes com a mesma. Vinculando a estratégia a longo prazo com os objectivos a médio e a curto prazo, este sistema foi desenvolvido para comunicar os diversos objectivos perseguidos por uma organização, reflectindo os elementos (tangíveis e intangíveis) que se consideram críticos para a sobrevivência e crescimento da organização.

Inicialmente concebido como um sistema de avaliação de desempenho, rapidamente passou a ser considerado como uma importante ferramenta de Contabilidade de Gestão Estratégica, por reflectir os factores críticos de sucesso e um conjunto de medidas financeiras e não financeiras estruturadas em quatro perspectivas básicas. Como tal, procuramos averiguar, através da aplicação de um questionário, qual a divulgação do BSC em Portugal.

$\mathrm{O}$ presente artigo encontra-se estruturado da seguinte forma. Inicialmente é feito um breve enquadramento teórico do BSC, realçando a sua complementaridade com outras filosofias de gestão. De seguida são apresentadas as principais conclusões do estudo empírico que realizamos no sentido de obter evidência sobre o conhecimento e utilização do BSC em Portugal e sobre a sua associação com variáveis como a localização geográfica, o sector de actividade, a dimensão organizacional e a internacionalização.

\section{ENQUADRAMENTO TEÓRICO DO BSC}

Os sistemas de avaliação do desempenho tradicionais baseados essencialmente em indicadores financeiros são, hoje em dia, considerados insuficientes para dar resposta às necessidades da gestão, podendo mesmo prejudicar a flexibilidade organizacional e a geração de valor económico futuro.

Com a finalidade de criar um novo modelo de medição de desempenho, Kaplan e Norton (1996) reuniram-se com representantes de dezenas de organizações de manufactura e serviços. As discussões conduziram à ampliação de um scorecard que já estava a ser aplicado, o qual continha para além de medidas financeiras, outras medidas não financeiras relacionadas com prazos de entrega a clientes, qualidade e ciclo produtivo.

Tal sistema passou a designar-se de Balanced Scorecard, centrado na representação equilibrada de medidas financeiras e não financeiras, organizadas em quatro perspectivas básicas: financeira; clientes; processos internos; e aprendizagem e crescimento. Estas fornecem respostas às seguintes questões (KAPLAN; NORTON, 1992):

a) como os clientes nos vêem? Que necessidades devem ser satisfeitas? (perspectiva do cliente)

b) em que nos devemos superar e sermos excelentes? (perspectiva interna)

c) como se deve aprender, inovar e crescer? (perspectiva de aprendizagem e crescimento)

d) que objectivos financeiros alcançar para maximizar o valor para os accionistas? (perspectiva financeira)

Para os autores, estas perspectivas não devem ser vistas como uma camisa-de-forças, ditando as circunstâncias do sector e a estratégia da empresa, a necessidade de agregar uma ou mais perspectivas complementares. Além disso, deverão estar inter-relacionadas de forma a reflectir a cadeia de relações causa-efeito nos chamados mapas estratégicos. Estes mapas fornecem uma representação visual dos objectivos críticos da empresa e das principais relações que se estabelecem entre eles (KAPLAN; NORTON, 2000). 
De acordo com Kaplan e Norton (1996), o poder real do BSC ocorre quando deixa de ser um sistema de medição do desempenho para se transformar num sistema de gestão estratégica baseado em quatro níveis:

a) esclarecimento e tradução da visão e estratégia da empresa;

b) comunicação e vinculação de objectivos e medidas estratégicas;

c) planeamento, estabelecimento de metas e afectação de recursos;

d) feedback e aprendizagem estratégica.

Face ao exposto, o BSC, como um sistema de gestão estratégica, facilita a compreensão e comunicação da missão e das estratégias organizacionais e a construção de um sistema de avaliação integrado com a estratégia que, através de relações de causa e efeito, evidencia a ligação entre a estratégia e indicadores chave de desempenho. Note-se que o BSC não abandona as medidas de natureza financeira, mas completa-as com outras não financeiras para impulsionar o desempenho organizacional.

\section{A COMPLEMENTARIDADE DO BSC COM OUTRAS FILOSOFIAS DE GESTÃO}

O BSC é uma ferramenta com grande capacidade para integrar e interagir, de forma lógica e coerente, com um conjunto de outras ferramentas utilizadas pelas organizações (PINTO, 2007). Assim, na opinião do autor é possível criar uma visão de sistema integrado, através da integração de algumas metodologias desenvolvidas nas organizações (Activity Based Costing/Activity Based Management (ABC/ABM); Customer Relationship Management (CRM); Six Sigma; Gestão do Capital Humano, entre outras), no BSC, que facilitará a gestão e execução da estratégia organizacional (Figura 1).

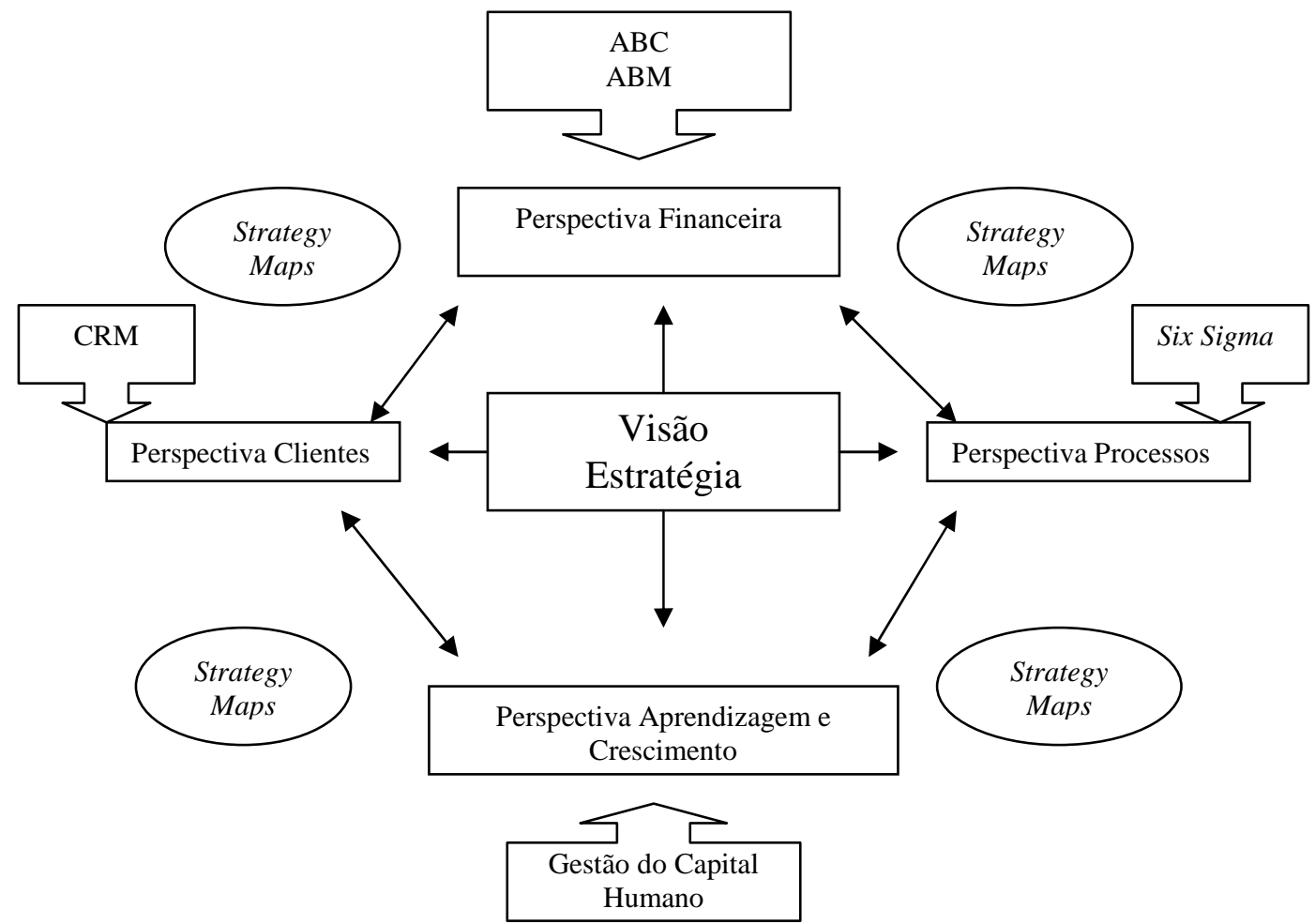

Figura 1 - Sistema integrado de gestão do desempenho Fonte: adaptado de Pinto (2007, p. 84).

\section{1 $A B C / A B M$}

Para Pinto (2007), o ABC/ABM podem ser integrados na perspectiva financeira, no 
sentido de que os outputs dos modelos $\mathrm{ABC} / \mathrm{ABM}$ são excelentes inputs para os mapas estratégicos, nomeadamente dados relacionados com o custo por unidade de produto, serviço, processo, estimulando acções e decisões que terão impactos no desempenho organizacional.

Segundo Jordan, Neves e Rodrigues (2002), a metodologia ABC, ao incorporar as relações de causa e efeito entre os níveis de recursos consumidos e as actividades que os utilizaram e ao permitir um apuramento mais completo e rigoroso dos custos e, consequentemente, dos resultados por segmento, é totalmente compatível com o BSC, particularmente com a perspectiva dos processos internos, permitindo um adequado acompanhamento e garantindo sustentabilidade dos valores financeiros dos processos e das actividades, ao lhes atribuir com maior rigor os níveis de consumo dos recursos.

Assim, na opinião dos autores, embora sejam conceitos que surgiram em épocas diferentes e que tenham sido tratados de forma independente, é recomendável a elaboração de modelos de gestão que os integrem de forma consistente, sobretudo porque se trata de sistemas de gestão complementares e não alternativos.

\subsection{CRM}

Na opinião de Pinto (2007), o CRM pode ser integrado na perspectiva do cliente do BSC para se atingirem as suas metas e objectivos, na medida em que o CRM permite obter informações sobre quanto investir em marketing para reter clientes, em qual o tipo de clientes investir mais, quais as actividades ou canais de marketing onde se deve investir mais, qual o tipo de oferta para os diferentes clientes, quais os segmentos que podem ser definidos e quais as suas características-chave.

De acordo com Peña (2003), a integração do CRM com o BSC permite vincular a estratégia e a rentabilidade da gestão de clientes. Assim, as etapas para a definição de um scorecard do CRM implicam a definição das perspectivas e objectivos do CRM; a selecção de indicadores estratégicos; a transmissão dos indicadores a todos os níveis da organização e a difusão dos objectivos do CRM na organização. Neste processo, além de se considerar as perspectivas preconizados por Kaplan e Norton, sugere-se a inclusão da perspectiva de segmentos para definir os segmentos sobre os quais se realizarão as actividades do CRM e as propostas de valor que se realizarão para cada um.

\subsection{Six Sigma/Lean Management}

A filosofia Six Sigma é uma evolução da teoria da qualidade total, centrando-se na capacidade que as organizações têm para gerar valor e de melhorar a sua produtividade e competitividade, através da eliminação de inúmeras actividades geradoras de custos. $\mathrm{O}$ conceito está associado à ideia de zero defeitos e foi desenvolvido em meados da década de 80 na Motorola agregando-o ao uso de ferramentas de qualidade total, ferramentas estatísticas para conseguir resultados (FERNANDES, 2005; ANDERSEN; LAWRIE; SAVIC, 2004).

Vários autores sugerem a utilização conjunta das metodologias Six Sigma e Lean Management (Lean Six Sigma), como forma de maximizar o valor percebido pelos accionistas e oferecido aos clientes e a velocidade dos processos. O Lean Management surgiu a partir das teorias de engenharia industrial no início da década de 50 no sistema de produção da Toyota, como contraponto à produção em massa, mas tem sido gradualmente aplicado nos mais diversos sectores de actividade.

Efectivamente, as vantagens da sua integração podem ser várias, atendendo que o Lean Management pressupõe a simplificação da forma como as organizações produzem e entregam valor aos seus clientes, assim como a eliminação dos desperdícios (prevenção dos defeitos, redução dos tempos de ciclo e economia de custos), ou seja, eliminar ou reduzir ao máximo as actividades que não agregam valor ao produto ou serviço, alinhando todas as fases 
de um processo de forma a permitir um fluxo contínuo e aumentar a rapidez na satisfação das necessidades dos clientes (FERNANDES, 2005; PYZDEK, 2003).

A utilização da estratégia Six Sigma com o BSC pressupõe um processo de melhoria contínua e, consequentemente, auxilia o processo de avaliação do desempenho através da identificação de problemas, as suas causas e as acções a levar a cabo para solucioná-los (KATO, 2003). À semelhança do BSC, o Lean Six Sigma é utilizado pelas organizações para medir e acompanhar o seu desempenho no alcance dos objectivos estratégicos.

Na opinião de Fernandes (2005, p. 61), o BSC "é tratado como um instrumento para avaliar o grau de alinhamento da organização com a sua direcção estratégica. A metodologia Lean Six Sigma deve funcionar como uma forma de operacionalizar as melhorias necessárias para esse alinhamento estratégico (...)". De acordo com o autor, as perspectivas do BSC podem ser utilizadas para avaliar a implementação de uma metodologia como o Lean Six Sigma (Quadro 1).

\begin{tabular}{|l|l|}
\hline Perspectivas do BSC & \multicolumn{1}{c|}{ Contribuição do Lean Six Sigma } \\
\hline Clientes & $\begin{array}{l}\text { Melhorar a qualidade, reduzir o tempo de entrega, melhorar a confiança no produto } \\
\text { ou serviço, aumentar o valor do produto ou serviço para o cliente. }\end{array}$ \\
\hline Processos Internos & $\begin{array}{l}\text { Selecção adequada dos processos a serem trabalhados nos projectos Lean Six Sigma, } \\
\text { mantendo a ênfase no valor para o cliente e nas necessidades do cliente. }\end{array}$ \\
\hline $\begin{array}{l}\text { Inovação e } \\
\text { Aprendizagem }\end{array}$ & $\begin{array}{l}\text { Melhoria das competências dos empregados, criação de uma cultura voltada para a } \\
\text { melhoria e para a criação de valor. }\end{array}$ \\
\hline Financeira & $\begin{array}{l}\text { Selecção de projectos com impacto financeiro capazes de gerar: aumento de receita, } \\
\text { redução de custos, melhor gestão de activos e melhor gestão de fluxos de caixa. }\end{array}$ \\
\hline
\end{tabular}

Quadro 1 - A contribuição do Lean Six Sigma para as perspectivas do BSC

Fonte: adaptado de Fernandes (2005, p. 63).

Para Andersen, Lawrie e Savic (2004), o BSC assegura que a gestão de topo preste atenção, em qualquer momento, para os elementos específicos da implementação do Six Sigma que não estão a funcionar de acordo com o planeado, proporcionando a vinculação entre estratégia e iniciativas de qualidade. Assim, o BSC fornece um mecanismo para que a gestão de topo acompanhe o sucesso na implementação de um processo Six Sigma, e a oportunidade de se efectuarem alterações à luz dos resultados alcançados.

A filosofia Six Sigma enquadra-se perfeitamente na perspectiva interna do BSC. Como nos refere Pinto (2007), o Six Sigma passou a incluir aspectos financeiros (custos e rentabilidade) no sistema de gestão da qualidade, procurando criar valor para o cliente e para o investidor.

\subsection{Capital Humano}

O capital humano é considerado pelas organizações como o activo mais importante, sendo fundamental a sua medição. Existe uma forte relação entre a Gestão do Capital Humano, a Gestão do Conhecimento, a Gestão do Capital Intelectual e a perspectiva de aprendizagem e crescimento do BSC, em concreto ao nível da gestão da retenção dos empregados e planeamento da força de trabalho (PINTO, 2007). A perspectiva de aprendizagem e crescimento envolve as mudanças e melhorias a realizar para concretizar a missão e visão empresarial.

Kaplan e Norton (1997, p. 133), ao reconhecerem que os resultados financeiros dependem do esforço individual do trabalhador para atingi-los, enfatizam a necessidade de investimento nas capacidades dos funcionários e no seu aperfeiçoamento, considerando que "as ideias que permitem melhorar os processos e o desempenho para os clientes cada vez mais emanam dos funcionários". Os autores ressaltam a necessidade de reciclagem dos funcionários para que as suas capacidades sejam mobilizadas no sentido dos objectivos 
organizacionais, atendendo que será improvável que as empresas sejam capazes de atingir as suas metas no longo prazo para os clientes e processos internos utilizando as tecnologias e capacidades actuais.

Assim, os objectivos financeiros, de clientes e dos processos internos só serão atingidos se a empresa tiver uma infra-estrutura que apoie esses objectivos e que provenha das pessoas (melhorar continuamente apenas permitirá à empresa manter a sua posição no mercado, hoje em dia, para crescer é necessário ir além dos procedimentos operacionais padronizados e dar especial atenção aos funcionários), sistemas e procedimentos organizacionais (é importante avaliar até que ponto o sistema de informação actual consegue responder às necessidades previstas, ou seja, qual a sua capacidade e adequação à empresa.

Devemos atender a informações sobre a qualidade, tempo, custo, acesso por parte dos funcionários aos dados dos clientes e o contacto que mantêm com estes) e motivação, empowerment $\mathrm{e}$ alinhamento (para o sucesso organizacional não basta que os funcionários tenham competências e um livre acesso às informações. É necessário que estejam motivados a agir no melhor interesse da empresa, participando no processo de tomada de decisão). Kaplan e Norton (1997) propõem, dentro do conceito de capacidade dos funcionários, que seja investigado o que denominam de Base Comum de Medidas Essenciais: satisfação, retenção e produtividade dos recursos humanos.

Em síntese, um dos pré-requisitos para a sobrevivência organizacional é o desenvolvimento e a renovação de capacidades relacionadas com os resultados de longo prazo que, na concepção de Olve, Roy e Wetter (1999), são garantidas por esta perspectiva. A manutenção e desenvolvimento do know-how são fundamentais para garantir a eficiência e eficácia necessárias aos processos, culminando com a criação de valor para os clientes e accionistas. Deve ser estimulada uma procura incessante de novas competências, especialmente uma competência superior específica (core competence).

Esta importância é evidenciada por Kaplan e Norton (1997), ao afirmarem que, embora o desinvestimento na formação dos recursos humanos possa melhorar os resultados financeiros a curto prazo, a longo prazo esse desempenho financeiro estará comprometido, uma vez que a organização deixa de ter capacidade para formar a infra-estrutura necessária para apoiar os processos que procuram a satisfação dos clientes e accionistas.

A relação entre o capital humano e o BSC é tal que levou diversos autores, entre os quais destacamos Becker, Huselid e Ulrich (2002), Rampersad (2004), Ulrich, Becker e Beatty (2005), Bencaleiro (2007), a desenvolver o chamado scorecard do capital humano, como forma de gerir o capital humano na execução da estratégia organizacional, ou seja, de vincular as pessoas, a estratégia e os resultados da empresa.

\section{ESTUDO EMPÍRICO}

\subsection{Objectivos do Estudo}

O estudo empírico que realizamos teve por objectivo avaliar a aplicabilidade e conhecimento do BSC em grandes empresas portuguesas pertencentes ao sector privado e identificar os principais benefícios derivados da adopção do BSC. Pretendeu-se, também, indicar as razões que levaram as empresas a não utilizar o BSC ou a abandonar a sua implementação e as principais motivações para a sua aplicação, comparando os resultados obtidos com estudos similares realizados anteriormente. Finalmente, procurou-se examinar quais são as empresas mais vocacionadas para a sua adopção, nomeadamente se a localização geográfica, o sector de actividade, a dimensão organizacional e a internacionalização da empresa são factores importantes. 


\section{2 Âmbito do Estudo: Problema e Hipóteses}

As empresas necessitam de implementar novos sistemas de medidas de desempenho que possibilitem o alinhamento das medidas às estratégias, complementando os tradicionais indicadores financeiros com indicadores de natureza não financeira. Desta forma, o BSC aparece no panorama empresarial como uma poderosa ferramenta para enfrentar a forte concorrência, resultante das grandes mudanças registadas na economia mundial. Mas estarão as empresas portuguesas a utilizar esta ferramenta no âmbito do seu processo de gestão?

Face ao exposto, definiram-se um conjunto de hipóteses de investigação. As duas primeiras hipóteses definidas estão relacionadas com a visita de Kaplan e Norton a Portugal. Assim, procuramos testar se existe maior propensão para a utilização e conhecimento do BSC nas cidades onde os autores apresentaram workshops, designadamente em Lisboa e no Porto. Como tal, definiram-se as seguintes hipóteses:

H1: Existe associação entre a localização geográfica e a adopção do BSC

$\mathrm{H} 2$ : Existe associação entre a localização geográfica e o conhecimento do BSC

De acordo com a teoria dos custos de propriedade há sectores que estão mais expostos à competitividade (VERRECCHIA, 1983). Atendendo ao facto de existirem sectores mais competitivos do que outros, depreende-se que a utilização e conhecimento de novas ferramentas de gestão, nomeadamente do BSC, poderá estar relacionada com os referidos sectores. Assim, definiram-se como hipóteses:

H3: Existe associação entre o sector de actividade e a adopção do BSC

H4: Existe associação entre o sector de actividade e o conhecimento do BSC

Embora nos últimos anos tenham sido apresentados estudos sobre a aplicação do BSC a pequenas e médias empresas, a literatura sugere que são essencialmente as grandes empresas que mais adoptam e conhecem esta ferramenta. A própria teoria positiva da contabilidade defende que as grandes empresas têm, em geral, sistemas de informação superiores (WATTS; ZIMMERMAN, 1990). Assim, seria importante testar, à semelhança do estudo realizado por Hoque e James (2000) e por Speckbacher, Bischof e Pfeiffer (2003), a relação entre o tamanho empresarial e a utilização e conhecimento do BSC:

H5: O tamanho organizacional está positivamente associado à adopção do BSC

H6: O tamanho organizacional está positivamente associado ao conhecimento do BSC

O BSC encontra-se amplamente difundido pelos diversos países do mundo. Cooke (1989) argumenta que empresas que operam em mais do que uma área geográfica tendem a ter melhores sistemas de controlo de gestão devido à maior complexidade das suas operações. Como tal, procuramos ver até que ponto a utilização e conhecimento do BSC poderá ser influenciada por empresas do grupo que já o aplicam ou pela abertura do mercado ao exterior:

H7: A internacionalização está positivamente associada à adopção do BSC

H8: A internacionalização está positivamente associada ao conhecimento do BSC

\subsection{Metodologia}

O método de recolha de dados desenvolveu-se através de um inquérito, consubstanciado num questionário, enviado, via postal, às 250 maiores empresas portuguesas, em finais do mês de Outubro de 2004. Estas empresas foram seleccionadas atendendo ao ranking das 500 maiores e melhores empresas (classificadas de acordo com o volume de vendas), publicado na edição especial da "Revista Exame" (2004). Esta escolha não é arbitrária nem aleatória, visto a literatura sugerir serem as grandes empresas que estarão à partida mais vocacionadas para aplicação do BSC. 
A preparação do questionário baseou-se em estudos anteriores, possuindo, na generalidade, uma estrutura muito semelhante à apresentada nos estudos de Sousa (2001) e de Speckbacher, Bischof e Pfeiffer (2003). Dos 250 questionários enviados obtivemos um total de 85 respostas, todas consideradas válidas, correspondendo a $34 \%$ do total de empresas inquiridas. Após recolha dos dados, estes foram organizados e tratados estatisticamente, recorrendo-se, para tal, ao programa informático SPSS (Statistical Package for the Social Sciences).

\section{RESULTADOS}

\subsection{Informações sobre a Implementação do BSC}

Da análise das 85 respostas, e com o intuito de averiguar em que medida está ou não generalizada a prática do BSC nas grandes empresas portuguesas, questionou-se sobre o estado de implementação do BSC. Verificámos que 44,7\% das empresas conhecem o BSC mas nunca tiveram contacto com este sistema, $12,9 \%$, não conhecem o BSC, 5,9\% já deram os primeiros passos ao nível da implementação, 18,8\% já possuem um BSC implementado, 4,7\% abandonaram a implementação e 12,9\% esperam implementá-lo futuramente (Tabela 1).

Tabela 1 - Utilização do BSC

\begin{tabular}{l|c|c}
\multicolumn{1}{c|}{ Estado de implementação } & N & \% \\
\hline Conhecem o BSC mas nunca tiveram contacto com este sistema & 38 & 44,7 \\
Não conhecem o BSC & 11 & 12,9 \\
Já foram dados os primeiros passos a nível de implementação & 5 & 5,9 \\
Possuem um BSC & 16 & 18,8 \\
Já o utilizaram mas abandonaram-no & 4 & 4,7 \\
Esperam implementá-lo futuramente & 11 & 12,9 \\
\hline Total & 85 & 100 \\
\hline
\end{tabular}

Os resultados obtidos revelam que o nível de implementação do BSC nas empresas portuguesas é bastante reduzido (representando menos de metade do total). Os inquiridos que assinalaram conhecer o BSC mas que não o implementaram ou que abandonaram a sua implementação, apontaram como principais razões o facto da empresa possuir outras ferramentas similares e estar satisfeita $(63,4 \%)$, seguido do facto do BSC não se ajustar à cultura e à missão da empresa $(14,6 \%)$ e de não se esperar obter grandes benefícios com a sua implementação $(14,6 \%)$. Como se pode observar na Tabela 2, foram ainda invocadas uma série de outras razões. 
Tabela 2 - Razões para a não adopção ou abandono do BSC

\begin{tabular}{l|c|c}
\hline \multicolumn{1}{c|c}{ Razões } & $\mathbf{N}$ & \% \\
\hline O BSC não se ajusta à cultura e missão empresarial & 6 & 14,6 \\
A empresa utiliza outras ferramentas similares e está satisfeita & 26 & 63,4 \\
Dificuldade na selecção das dimensões básicas do BSC e no estabelecimento de & 2 & 4,9 \\
inter-relações entre elas & & 12,2 \\
Dificuldade de definição das estratégias em termos tão claros quanto os & 5 & 9,8 \\
necessários para construir o BSC & & \\
Dificuldade de representação das várias facetas da estratégia da empresa através & 4 & \\
de um conjunto crítico de medidas quantitativas & 6 & 14,6 \\
Não se esperam obter grandes benefícios & 1 & 2,4 \\
Exige custos de implementação demasiado grandes & 1 & 2,4 \\
Exige um consumo excessivo de tempo & 3 & 7,3 \\
Incompreensão dos seus impactos a nível organizacional & 3 & 7,3 \\
Inadequado suporte tecnológico & 1 & 2,4 \\
Aversão à mudança e ao risco & 1 & 2,4 \\
Falta de compromisso por parte do pessoal & 1 & 2,4 \\
Dificuldade em avaliar a importância relativa das medidas & 4 & 9,8 \\
Dificuldade em decompor os objectivos para os níveis inferiores & 3 & 7,3 \\
Requer um sistema de informação bastante desenvolvido & 2 & 4,9 \\
Outra & & \\
\hline
\end{tabular}

No que concerne ao processo de implementação propriamente dito, destaca-se a implementação ao nível da empresa, seguida da Unidade Estratégica de Negócio (UEN) e do departamento ou secção (Tabela 3). Estes resultados não vão ao encontro daquilo que foi preconizado por Kaplan e Norton (1996), na medida em que os autores recomendam o desdobramento em cascata do processo de implementação do BSC pelos vários níveis organizacionais.

Tabela 3 - Nível de implementação do BSC

\begin{tabular}{|c|c|c|}
\hline Nível & $\mathbf{N}$ & $\%$ \\
\hline Empresa & 20 & 69 \\
\hline UEN & 8 & 27,6 \\
\hline Departamento/Secção & 8 & 27,6 \\
\hline Centro de Actividade & 2 & 6,9 \\
\hline
\end{tabular}

Procurando obter uma ideia das razões que levaram as empresas a implementar o BSC, apresentamos aos inquiridos uma lista de razões de diversa índole, solicitando-lhes que indicassem o grau de importância [escala graduada de 1 (totalmente sem importância) a 5 (extremamente importante)]. A Tabela 4 sintetiza os resultados obtidos.

$\mathrm{Na}$ interpretação destes resultados deverá ter-se em conta que, regra geral, os inquiridos atribuíram alguma importância a todas as razões, destacam-se o facto do BSC permitir criar ligações entre a estratégia e os objectivos individuais, das equipas e das unidades de negócio, de possibilitar a comunicação da estratégia até ao nível operacional, a melhoria registada ao nível da compreensão dos indutores do sucesso estratégico, o alinhamento do desempenho dos empregados com os objectivos estratégicos e a medição mais eficaz do desempenho não financeiro. 
Tabela 4 - Razões para a implementação do BSC

\begin{tabular}{l|c|c}
\hline \multicolumn{1}{c|}{ Razões } & Média & $\begin{array}{c}\text { Desvio } \\
\text { Padrão }\end{array}$ \\
\hline Criar ligações entre a estratégia e os objectivos individuais das equipas e & 4,52 & 0,643 \\
unidades de negócio & 4,22 & 0,751 \\
Comunicar a estratégia até ao nível operacional & 4,22 & 0,577 \\
Melhorar a compreensão dos indutores do sucesso estratégico & 4,04 & 0,759 \\
Alinhar o desempenho dos empregados com os objectivos estratégicos & 4,00 & 0,784 \\
Medição mais eficaz do desempenho não financeiro & 3,81 & 0,786 \\
Alterar a natureza do processo de feedback e de revisão estratégica & 3,81 & 0,736 \\
Melhorar o estabelecimento das iniciativas prioritárias e a afectação de recursos & 3,74 & 1,059 \\
Redefinir o sistema de controlo de gestão da empresa & 3,63 & 0,967 \\
Alinhar o sistema de incentivos e recompensas com o desempenho & 3,59 & 1,010 \\
Medição mais eficaz do desempenho financeiro & 3,52 & 0,893 \\
Lutar contra a crescente competitividade & & \\
\hline
\end{tabular}

De realçar que estas variáveis, a par da melhoria no estabelecimento de iniciativas prioritárias e na afectação de recursos, são as que apresentam um desvio padrão inferior o que reflecte convergência de opinião. De notar, ainda, que os inquiridos divergem mais nas suas opiniões nas afirmações de redefinição do sistema de controlo de gestão da empresa, alterando a natureza dos tradicionais processos de planeamento e gestão orçamental, e ao nível da medição mais eficaz do desempenho financeiro, com um desvio padrão de 1,059 e de 1,010 , respectivamente.

Foi possível, assim, apurar que entre as razões que motivam as empresas a adoptar o BSC foi atribuída uma maior importância às que seguem mais de perto a linha de pensamento de Kaplan e Norton (2001) reflectida nos princípios fundamentais das organizações focalizadas na estratégia: tradução da estratégia em termos operacionais; alinhamento estratégico; transformação da estratégia em tarefa de todos; conversão da estratégia em processo contínuo e mobilização da mudança por meio da liderança executiva.

\subsection{Informações sobre o conteúdo do BSC}

Neste ponto pretendemos averiguar a forma como o BSC está construído. As respostas obtidas indicam, relativamente às perspectivas, que a maioria das empresas possuem ou planeiam possuir as quatro perspectivas propostas por Kaplan e Norton. Apesar de todas as empresas que responderam a esta questão terem afirmado possuir ou que planeiam possuir a perspectiva financeira, apenas quinze empresas utilizam ou esperam utilizar a perspectiva de aprendizagem e crescimento.

Facto preocupante, mas não estranho, quando esta perspectiva é indicada por Kaplan e Norton (1996) como a mais importante, mas também a mais difícil de implementar. Como refere Sousa (2001), isto pode desviar a atenção das empresas para os aspectos operacionais de curto prazo, em vez de se centrarem nos objectivos estratégicos de longo prazo e na obtenção de vantagens competitivas.

De salientar, ainda, que uma empresa do sector distributivo revelou ter substituído a perspectiva dos clientes pela perspectiva do mercado, por sua vez, uma empresa do ramo da construção designou a perspectiva de aprendizagem e crescimento por perspectiva das pessoas e que apenas três empresas mencionaram ter utilizado outras perspectivas além das recomendadas por Kaplan e Norton. A perspectiva dos recursos humanos foi apontada por duas empresas e a perspectiva das infra-estruturas foi referida por uma empresa. Como estas empresas não assinalaram a perspectiva de aprendizagem e crescimento, muito provavelmente, apenas adoptaram uma outra denominação para a referida perspectiva. 
Tabela 5 - Perspectivas incluídas ou a incluir no BSC

\begin{tabular}{l|c|cc}
\hline & Perspectivas & N & \% \\
\hline Financeira & & 27 & 100 \\
Clientes & & 21 & 77,8 \\
Processos Internos & 25 & 92,6 \\
Aprendizagem e Crescimento & 15 & 55,6 \\
Outras & 3 & 11,1 \\
\hline
\end{tabular}

$\mathrm{Na}$ análise dos benefícios, e sendo esta questão de resposta múltipla, grande parte das empresas assinalaram mais do que um benefício (Tabela 6).

Tabela 6 - Benefícios obtidos com a implementação do BSC

\begin{tabular}{l|c|c}
\multicolumn{1}{c}{ Benefícios } & $\mathbf{N}$ & $\mathbf{\%}$ \\
\hline Facilita a implementação da estratégia e o seu desenvolvimento adicional & 18 & 69,2 \\
Clarificação e comunicação da estratégia & 20 & 76,9 \\
Desenvolvimento de um sistema consistente de objectivos & 20 & 76,9 \\
Melhoria na medição do desempenho organizacional & 17 & 65,4 \\
Aumento dos resultados económico-financeiros & 9 & 34,6 \\
Melhoria no alinhamento entre objectivos estratégicos e acções & 22 & 84,6 \\
Proporciona um suporte para a implementação de mudanças & 8 & 30,8 \\
Obtenção de sinergias entre unidades, áreas e sectores & 6 & 23,1 \\
Melhoria na aprendizagem estratégica & 14 & 53,8 \\
Melhoria na atenção prestada aos clientes & 10 & 38,5 \\
Construção das bases para um sistema de incentivos & 11 & 42,3 \\
Realce dos indicadores não financeiros de desempenho & 13 & 50 \\
\hline
\end{tabular}

Nota-se que $84,6 \%$ das empresas destacaram como aspecto positivo a melhoria no alinhamento entre objectivos estratégicos e acções, seguem-se benefícios relacionados com a clarificação e comunicação da estratégia, bem como com o desenvolvimento de um sistema consistente de objectivos, ambos apontados em 76,9\% dos casos. Merece ainda especial destaque o facto do BSC facilitar a implementação da estratégia e o seu desenvolvimento adicional $(69,2 \%)$ e a melhoria na medição do desempenho organizacional $(65,4 \%)$. Importa sublinhar que nenhuma empresa adicionou outros benefícios para além dos contidos na lista e que os benefícios seleccionados em menor número foram a obtenção de sinergias entre unidades, áreas e sectores, bem como o suporte para a implementação de mudanças.

\subsection{Análise Bivariada}

No âmbito deste estudo julgamos pertinente averiguar se estatisticamente existe correlação entre algumas variáveis, designadamente entre o sector de actividade e a localização geográfica. No sentido de testar as hipóteses definidas relativamente à associação de um conjunto de variáveis com a utilização e conhecimento do BSC iremos realizar uma análise bivariada mediante a aplicação do teste não paramétrico de independência do Quiquadrado de Pearson $\left(\chi^{2}\right)$ baseado na tabela de contingência. Ressalte-se, no entanto, que este teste está condicionado à verificação de um conjunto de pressupostos, designadamente que não existam células com um valor esperado menor que 1 nem que mais de $20 \%$ das células tenham valores esperados menores que 5 (PESTANA; GAGEIRO, 2003).

No sentido de reduzirmos a dispersão dos nossos dados efectuamos um conjunto de agregações e criamos novas variáveis. Assim, quanto ao estado de implementação do BSC decidimos criar dois grupos, um constituído pelas empresas que efectivamente já possuem o BSC ou que já iniciaram a sua implementação e um segundo grupo que inclui os que não utilizam o BSC. Neste último grupo agregamos aqueles que assinalaram conhecer o BSC mas que nunca tiveram contacto com este sistema, os que não conhecem o BSC, os que já o utilizaram mas abandonaram e os que esperam implementá-lo futuramente. Criamos, ainda, 
uma nova variável onde separamos aqueles que conhecem o BSC daqueles que o desconhecem.

Ao nível da associação entre a utilização e conhecimento do BSC e a localização geográfica (H1 e H2), também efectuamos algumas agregações dada a dispersão da nossa amostra por todo o território nacional. Atendendo ao facto da maioria das empresas pertencer à região de Lisboa e Vale do Tejo (LVT), optamos por separar estas do resto do país (Tabela 7). Como são cumpridas as condições de aplicabilidade e o teste não é significativo ( $p$ value $\left.=0,658 ; \chi^{2}=0,196\right)$, concluímos não haver associação entre as variáveis para um nível de significância de 5\%. Não obstante, note-se que das 21 empresas que utilizam ou já iniciaram o processo de adopção do BSC, 61,9\% pertencem à região de LVT. No entanto, também é nesta região que se verifica uma grande percentagem de empresas que não utilizam o BSC $(67,2 \%)$.

Tabela 7 - Utilização do BSC por localização geográfica

\begin{tabular}{|c|c|c|c|c|c|}
\hline & & & \multicolumn{2}{|c|}{ Utilização do BSC } & \multirow[b]{2}{*}{ Total } \\
\hline & & & $\begin{array}{c}\text { Utiliza ou já deu os } \\
\text { primeiros passos }\end{array}$ & $\begin{array}{c}\text { Não } \\
\text { Utiliza }\end{array}$ & \\
\hline \multirow{5}{*}{$\begin{array}{l}\text { Localização } \\
\text { Geográfica }\end{array}$} & LVT & Casos & 13 & 43 & 56 \\
\hline & & \% Utilização do BSC & $61,9 \%$ & $67,2 \%$ & $65,9 \%$ \\
\hline & & Resíduo Ajustado &,- 4 & ,4 & \\
\hline & Resto do país & Casos & 8 & 21 & 29 \\
\hline & & $\begin{array}{l}\text { \% Utilização do BSC } \\
\text { Resíduo Ajustado }\end{array}$ & $\begin{array}{c}38,1 \% \\
\quad, 4\end{array}$ & $\begin{array}{c}32,8 \% \\
-, 4\end{array}$ & $34,1 \%$ \\
\hline \multicolumn{2}{|l|}{ Total } & $\begin{array}{l}\text { Casos } \\
\% \text { Utilização do BSC }\end{array}$ & $\begin{array}{c}21 \\
100,0 \%\end{array}$ & $\begin{array}{c}64 \\
100,0 \%\end{array}$ & $\begin{array}{c}85 \\
100,0 \%\end{array}$ \\
\hline
\end{tabular}

Ao nível do conhecimento do BSC por localização geográfica (Tabela 8) apesar do teste do Qui-quadrado ser significativo ( $p$-value $=0,027 ; \chi^{2}=4,898$ ), os resultados são inconclusivos porque é violado um dos pressupostos (25\% das células têm valor esperado inferior a 5). Contudo, não podemos deixar de fazer uma análise descritiva dos resultados, sobressaindo, no que se refere ao conhecimento, a região de LVT $(70,3 \%)$ comparativamente com o resto do país $(29,7 \%)$.

Tabela 8 - Conhecimento do BSC por localização geográfica

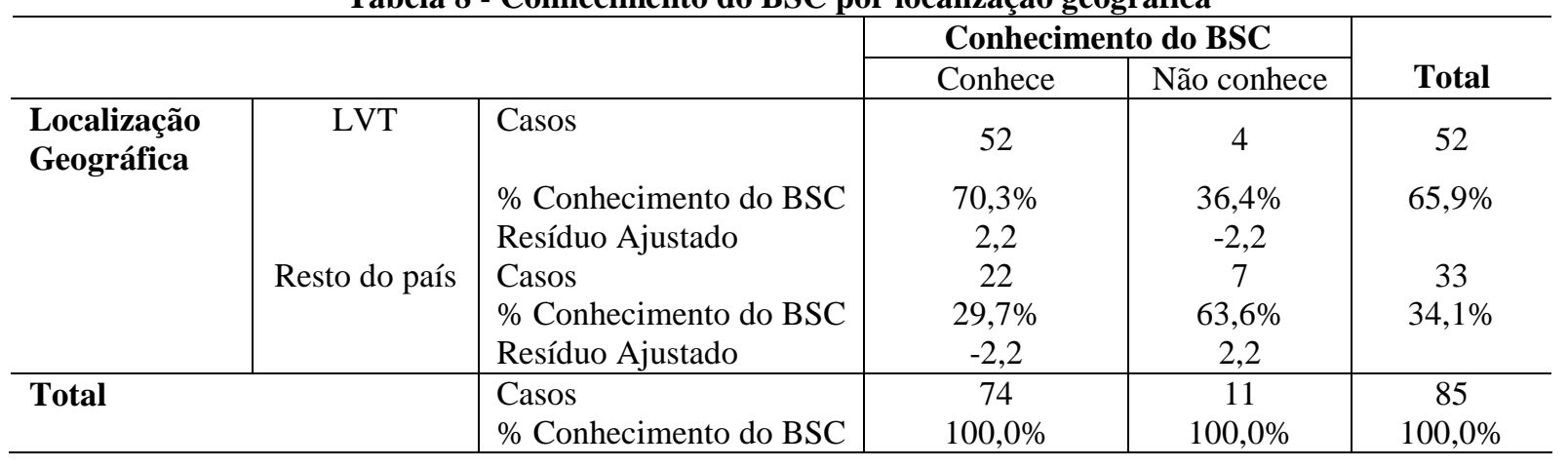

Para testarmos a associação entre a utilização e conhecimento do BSC e o sector de actividade (H3 e H4) também efectuamos alguns agrupamentos, pelo que decidimos agrupar as empresas que pertencem ao sector secundário (incluindo as empresas industriais e do sector da construção) e as empresas pertencentes ao sector terciário (incluindo as restantes empresas) para prosseguir com a nossa análise (Tabela 9). 
Tabela 9 - Utilização do BSC por sector

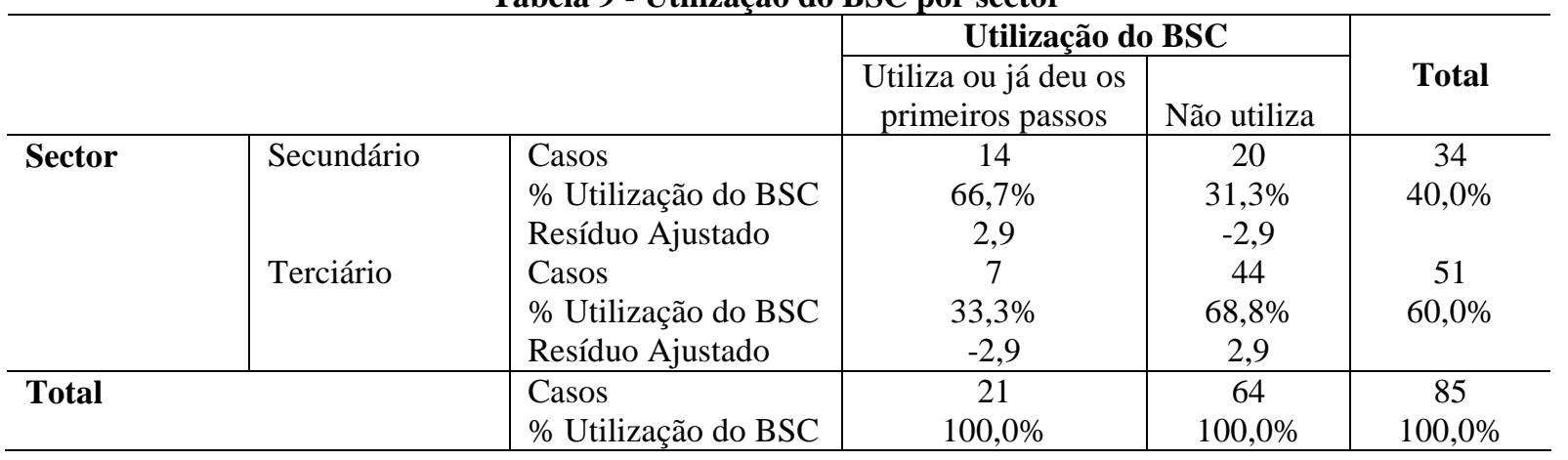

Como se observa na Tabela 10, o teste do Qui-quadrado, com 1 grau de liberdade e para um nível de significância de $5 \%$, é significativo $(p$-value $=0,004)$, indicando que existe associação entre o sector e a utilização do BSC, em particular verificamos uma maior proporção de utilização no sector secundário $(66,7 \%)$, sendo as empresas do sector terciário as que menos utilizam $(68,8 \%)$. Isto pode revelar a necessidade que aquelas empresas sentem em se tornarem mais competitivas, utilizando novas ferramentas que lhes permitam enfrentar a forte concorrência empresarial.

Tabela 10 - Teste do Qui-quadrado de Pearson

\begin{tabular}{l|c|c|c}
\hline & Valor & GL & Nível Sig. (bilateral) \\
\hline Qui-quadrado de Pearson & $8,264(*)$ & 1 &, 004 \\
\hline Correcção de Continuidade & 6,854 & 1 &, 009 \\
\hline Número de Casos Válidos & 85 & & \\
\hline
\end{tabular}

0 células (,0\%) têm valor esperado inferior a 5 . O mínimo valor esperado é 8,40.

Como o teste do Qui-quadrado não indica a intensidade ou direcção da associação, testando apenas a hipótese de independência entre as variáveis, é necessário recorrer a outras medidas. No nosso caso, como estamos na presença de variáveis nominais devemos utilizar como medida da intensidade da associação o V de Cramer (PESTANA; GAGEIRO, 2003). O cálculo da referida medida revelou a existência de uma associação interessante ( $V$ de Cramer=0,312), evidenciando uma relação entre as variáveis.

No que respeita ao conhecimento do BSC por sector (Tabela 11), regra geral, quer as empresas do sector secundário $(44,6 \%)$, quer as do sector terciário $(55,4 \%)$ conhecem o BSC. É curioso notar que das 11 empresas que não conhecem, a quase totalidade $(90,9 \%)$ pertence ao sector terciário. Ao nível do teste do Qui-quadrado, como o valor de prova $(0,025)$, a que corresponde um $\chi^{2}$ de 5,030, é inferior ao nível de significância $(0,05)$, o teste apresenta-se significativo. No entanto, existe violação dos pressupostos (1 célula tem valor esperado inferior a 5), não nos permitindo retirar ilações sobre a associação entre as variáveis.

Tabela 11 - Conhecimento do BSC por sector

\begin{tabular}{|c|c|c|c|c|c|}
\hline & & & \multicolumn{2}{|c|}{ Conhecimento do BSC } & \multirow[b]{2}{*}{ Total } \\
\hline & & & Conhece & Não conhece & \\
\hline Sector & $\begin{array}{l}\text { Secundário } \\
\text { Terciário }\end{array}$ & $\begin{array}{l}\text { Casos } \\
\text { \% Conhecimento do BSC } \\
\text { Resíduo Ajustado } \\
\text { Casos } \\
\text { \% Conhecimento do BSC } \\
\text { Resíduo Ajustado }\end{array}$ & $\begin{array}{c}33 \\
44,6 \% \\
2,2 \\
41 \\
55,4 \% \\
-2,2\end{array}$ & $\begin{array}{c}1 \\
9,1 \% \\
-2,2 \\
10 \\
90,9 \% \\
2,2 \\
\end{array}$ & $\begin{array}{c}34 \\
40,0 \% \\
51 \\
60,0 \%\end{array}$ \\
\hline Total & & $\begin{array}{l}\text { Casos } \\
\% \text { Conhecimento do BSC }\end{array}$ & $\begin{array}{c}74 \\
100,0 \%\end{array}$ & $\begin{array}{c}11 \\
100,0 \%\end{array}$ & $\begin{array}{c}85 \\
100,0 \%\end{array}$ \\
\hline
\end{tabular}




\subsection{Análise Multivariada}

Atendendo à dispersão dos dados da nossa amostra, decidimos definir duas novas variáveis independentes: dimensão e internacionalização. Para tal, recorremos à análise factorial, à aplicação do teste de esfericidade de Bartlett e do teste de normalização KaiserMeyer-Olkin (KMO).

\subsubsection{Dimensão}

A literatura refere com frequência que são as grandes empresas as que estão em melhores condições para adoptar o BSC, em virtude de uma estrutura organizacional mais descentralizada, de uma maior especialização de funções e processos, de mais recursos financeiros e de uma melhor coordenação e comunicação de problemas (BRAAM e NIJSSEN, 2004; SPECKBACHER, BISCHOF e PFEIFFER, 2003; HOQUE e JAMES, 2000; CHENHALL e LANGFIELD-SMITH, 1998). Apesar de já existirem estudos que refiram que o BSC é perfeitamente aplicável às pequenas empresas, tal como refere Sousa (2001), estas têm necessidades, produtos e processos diferentes das grandes empresas e podem não estar a enfrentar um ambiente tão competitivo. Além disso, dever-se-á atender à limitação registada ao nível dos recursos necessários para levar a cabo o processo de implementação do BSC.

Assim, procuramos testar a relação entre o tamanho organizacional (medido através do volume de negócios, do total do activo e do número de empregados) e a utilização e conhecimento do BSC em Portugal. Tratando-se de variáveis quantitativas, procuramos definir uma nova variável, denominada "dimensão", através da utilização da análise factorial. Inicialmente efectuamos um teste à normalidade da distribuição (Tabela 12) para obtermos indicação do tipo de coeficiente de correlação a utilizar na nossa análise. No nosso caso, excluindo os casos que têm valores desconhecidos para qualquer uma das variáveis em análise, temos uma amostra de 75 casos. Assim, verificamos que, para um nível de significância de 5\%, o teste Kolmogorov-Smirnov (K-S), é significativo ( $p$-value $<0,05$ ), ou seja, rejeitamos a hipótese da normalidade.

Tabela 12 - Teste à normalidade das variáveis relativas ao tamanho organizacional

\begin{tabular}{l|c|c|c|c|c|cc}
\hline & \multicolumn{3}{|c}{ Kolmogorov-Smirnov (*) } & \multicolumn{4}{c}{ Shapiro-Wilk } \\
\cline { 2 - 7 } & Estatística & GL & Sig. & Estatística & GL & Sig. \\
\hline Total do Activo &, 319 & 75 &, 000 &, 519 & 75 &, 000 \\
Volume de Negócios &, 362 & 75 &, 000 &, 340 & 75 &, 000 \\
Número de Trabalhadores &, 373 & 75 &, 000 &, 279 & 75 &, 000 \\
\hline
\end{tabular}

* Correcção de Lilliefors

Não havendo normalidade devemos usar as correlações de Spearman. Como exposto na Tabela 13, todas as correlações são significativas ( $p$-value $<0,05)$, ou seja, todas as medidas podem formar a variável "dimensão".

Tabela 13 - Correlações entre as variáveis que reflectem a dimensão

\begin{tabular}{|c|c|c|c|c|}
\hline & & $\begin{array}{c}\text { Total do } \\
\text { Activo }\end{array}$ & $\begin{array}{l}\text { Volume de } \\
\text { negócios }\end{array}$ & $\begin{array}{l}\text { Número de } \\
\text { trabalhadores }\end{array}$ \\
\hline \multirow[t]{2}{*}{ Total do Activo } & $\begin{array}{l}\text { Coeficiente de Correlação de } \\
\text { Spearman }\end{array}$ & 1,000 &, $728(* *)$ &, $416(* *)$ \\
\hline & Sig. (bilateral) & . &, 000 & 000 \\
\hline \multirow[t]{2}{*}{ Volume de Negócios } & $\begin{array}{l}\text { Coeficiente de Correlação de } \\
\text { Spearman }\end{array}$ &, $728(* *)$ & 1,000 &, $337(* *)$ \\
\hline & Sig. (bilateral) &, 000 & & ,003 \\
\hline \multirow{2}{*}{$\begin{array}{l}\text { Número de } \\
\text { Trabalhadores }\end{array}$} & Coeficiente de Correlação de &, $416(* *)$ &, $337(* *)$ & 1,000 \\
\hline & $\begin{array}{l}\text { Spearman } \\
\text { Sig. (bilateral) }\end{array}$ &, 000 &, 003 & \\
\hline
\end{tabular}

** Correlação significativa a um nível de 0,01 (bilateral) 
Estamos, portanto, em condições de prosseguir com a análise factorial que irá procurar resumir a informação contida nas variáveis originais num índice que reflicta a dimensão empresarial. Como podemos observar na Tabela 14, a adequabilidade da análise factorial às variáveis em análise é razoável (KMO de 0,539). Por sua vez, o teste de Bartlett apresenta estatística significativa ( $p$-value<0,005), indicando a rejeição da hipótese da matriz de correlações ser a matriz identidade, isto é, existe correlação significativa entre as variáveis, o que permite continuar com a análise factorial.

Tabela 14 - Teste de KMO e Bartlett

\begin{tabular}{l|l|c}
\hline Medida da adequação da amostragem $K M O$ & Aprox. Qui-quadrado &, 539 \\
\hline Teste de esfericidade de Bartlett & GL & 3 \\
\hline & Sig. &, 000 \\
\hline
\end{tabular}

A Tabela 15 mostra a parte de cada variável que ficou ou está presente nas componentes que foram retidas (PEREIRA, 1999). Podemos observar que a variável que mais fracamente vai explicar a "dimensão" é o número de trabalhadores porque é a que tem uma variação comum mais baixa. Por outro lado, registamos valores altos para as variáveis total do activo e volume de negócios, reflectindo uma forte relação entre essas variáveis e o factor retido, ou seja, estes itens são explicados satisfatoriamente pelo factor solução.

Tabela 15 - Comunalidades

\begin{tabular}{l|c|c}
\hline & Inicial & Extracção \\
\hline Total do Activo & 1,000 &, 700 \\
Volume de Negócios & 1,000 &, 856 \\
Número de Trabalhadores & 1,000 &, 457 \\
\hline
\end{tabular}

Relativamente à variância total explicada (que nos dá o número de factores a reter), como se verifica na Tabela 16, pelo critério Kaiser apenas retemos um factor, dado existir apenas um valor próprio (eigenvalue) superior a 1. A componente retida explica $67 \%$ da variância das variáveis originais, ou seja, só $67 \%$ é que fica representada na variável "dimensão". Utilizamos o método de extracção das componentes principais para a obtenção destes valores.

Tabela 16 - Variância total explicada

\begin{tabular}{c|c|c|c|c|c|c|}
\hline \multirow{2}{*}{ Componentes } & \multicolumn{4}{|c|}{ Eigenvalues Iniciais } & \multicolumn{2}{c|}{ Extracção da soma dos pesos ao quadrado } \\
\cline { 2 - 7 } & Total & \% Variância & Acumulada & Total & \% Variância & Acumulada \\
\hline 1 & 2,014 & 67,135 & 67,135 & 2,014 & 67,135 & 67,135 \\
2 &, 751 & 25,043 & 92,178 & & & \\
3 &, 235 & 7,822 & 100,000 & & & \\
\hline
\end{tabular}

Na Tabela 17 temos a correlação entre cada variável e a componente (loadings). Todas as variáveis se correlacionam positivamente, ou seja, quanto maior o total do activo, do volume de negócios e do número de trabalhadores, maior a dimensão da empresa. Ressalte-se, no entanto, e como se previa, o valor mais baixo registado ao nível da variável número de trabalhadores $(0,676)$. Face ao exposto, verificamos que a análise factorial proporciona uma boa medida do tamanho das empresas, criando-se uma nova variável ("dimensão") constituída pelos scores desta componente, os quais possibilitam a ligação das respostas dadas por cada inquirido às variáveis envolvidas e à própria componente. 
Tabela 17 - Matriz da componente

\begin{tabular}{l|c}
\hline \multirow{2}{*}{ Total do Activo } & Componente* \\
\cline { 2 - 2 } Volume de Negócios & 1 \\
Número de Trabalhadores &, 837 \\
\hline
\end{tabular}

* Uma componente extraída

\subsubsection{Internacionalização}

Um dos aspectos que decidimos explorar foi a relação entre a internacionalização e a predisposição para a adopção do BSC, ou seja, verificar até que ponto o BSC pode ser aplicado por influência de empresas do grupo que já o aplicam ou pela abertura do mercado (enfrentando uma forte pressão competitiva).

Efectuamos três questões com o intuito de averiguar o nível de internacionalização das empresas. Procuramos obter informação sobre o número de filiais estrangeiras, sobre a facturação para mercados externos e sobre a percentagem de participação estrangeira no capital da empresa. Em relação a estas variáveis procuramos, através da utilização da análise factorial, definir uma nova variável, denominada internacionalização, utilizando os mesmos procedimentos descritos anteriormente. Ao nível da análise factorial, considerando os casos que têm valores conhecidos para todas as variáveis em análise, temos uma amostra de 59 casos (continuando a ser válido o teste $\mathrm{K}-\mathrm{S}$ ). O teste à normalidade das variáveis relativas à internacionalização permitiu-nos concluir que não se verifica a normalidade (Tabela 18), pelo que temos de usar as correlações não paramétricas de Spearman.

Tabela 18 - Teste à normalidade das variáveis relativas à internacionalização

\begin{tabular}{l|c|c|c|c|c|c}
\hline & \multicolumn{3}{|c|}{ Kolmogorov-Smirnov(*) } & \multicolumn{3}{c}{ Shapiro-Wilk } \\
\cline { 2 - 7 } & Estatística & GL & Sig. & Estatística & GL & Sig. \\
\hline Número de Filiais &, 419 & 59 &, 000 &, 204 & 59 &, 000 \\
$\begin{array}{l}\text { Facturação para } \\
\text { Mercados Externos }\end{array}$ &, 390 & 59 &, 000 &, 288 & 59 &, 000 \\
$\begin{array}{l}\text { Percentagem de } \\
\text { Capital Estrangeiro }\end{array}$ &, 292 & 59 &, 000 &, 723 & 59 &, 000 \\
\hline
\end{tabular}

* Correcção de Lilliefors

No que concerne às correlações entre as variáveis que reflectem a internacionalização (Tabela 19), verificamos que a facturação para mercados externos correlaciona-se com o número de filiais ( $p$-value $=0,001)$ mas não com o \% de capital estrangeiro ( $p$-value $=0,260)$. $\mathrm{O}$ $\%$ de capital estrangeiro relaciona-se fraca e negativamente com o número de filiais $(p$ value $=0,043$ ), ou seja, quanto maior o número de filiais estrangeiras, menor o $\%$ de capital estrangeiro. Em face destes resultados decidimos não considerar o \% de capital estrangeiro na análise factorial, já que só as outras variáveis dão informação sobre a internacionalização.

Tabela 19 - Correlações entre as variáveis que reflectem a internacionalização

\begin{tabular}{l|l|c|c|c}
\hline \multicolumn{2}{l}{} & $\begin{array}{c}\text { Número de } \\
\text { Filiais }\end{array}$ & $\begin{array}{c}\text { Facturação } \\
\text { mercado externo }\end{array}$ & $\begin{array}{c}\% \text { de capital } \\
\text { estrangeiro }\end{array}$ \\
\hline Número de Filiais & $\begin{array}{l}\text { Coeficiente de Correlação } \\
\text { de Spearman } \\
\text { Sig. (bilateral) }\end{array}$ & 1,000 &, $407(* *)$ &,$- 265(*)$ \\
Facturação para & $\begin{array}{l}\text { Coeficiente de Correlação } \\
\text { de Spearman } \\
\text { Mercados Externos }\end{array}$ &, $407(* *)$ &, 001 &, 043 \\
Percentagem de Capital & $\begin{array}{l}\text { Coeficiente de Correlação } \\
\text { de Spearman } \\
\text { Estrangeiro }\end{array}$ &,$- 265(*)$ &, 000 &, 149 \\
& Sig. (bilateral) &, 043 &, 260 & 1,000 \\
\hline
\end{tabular}

** Correlação significativa a um nível de 0,01 (bilateral)

* Correlação significativa a um nível de 0,05 (bilateral) 
Como se pode observar na Tabela 20, a medida da adequação da amostragem continua baixa (KMO de 0,5), no entanto, este valor ainda é aceitável para prosseguir com a análise. Por sua vez, o teste de esfericidade de Bartlett apresenta estatística não significativa ( $p$ value $>0,05)$, não existindo correlação significativa entre as variáveis, não se aconselhando que se continue com a análise. Não obstante, este teste é bastante influenciado pelo tamanho da amostra. Como tal, e salvaguardando as conclusões obtidas, decidimos prosseguir com a análise.

Tabela 20 - Teste de KMO e Bartlett

\begin{tabular}{l|l|c}
\hline \multicolumn{2}{l|}{} &, 500 \\
\hline Teste de esfericidade de Bartlett & Aprox. Qui-quadrado &, 062 \\
\hline & GL & 1 \\
\hline & Sig. &, 804 \\
\hline
\end{tabular}

Ao nível da análise das comunalidades (Tabela 21) verificamos que ambas as variáveis participam de igual modo na componente, embora não apresentem valores muito elevados das comunalidades, ou seja, não têm uma relação muito forte com os factores retidos.

Tabela 21 - Comunalidade

\begin{tabular}{l|c|c}
\hline & Inicial & Extracção \\
\hline Número de Filiais & 1,000 &, 516 \\
Facturação para Mercados Externos & 1,000 &, 516 \\
\hline
\end{tabular}

Ressalte-se, com efeito, que só representam $51,6 \%$ da variabilidade dos dados originais (Tabela 22).

Tabela 22 - Variância total explicada

\begin{tabular}{c|c|c|c|c|c|c}
\hline \multirow{2}{*}{ Componentes } & \multicolumn{3}{|c|}{ Eigenvalues Iniciais } & \multicolumn{2}{c}{ Extracção da soma dos pesos ao quadrado } \\
\cline { 2 - 6 } & Total & $\begin{array}{c}\% \\
\text { Variância }\end{array}$ & $\begin{array}{c}\% \\
\text { Acumulada }\end{array}$ & Total & $\begin{array}{c}\% \\
\text { Variância }\end{array}$ & \begin{tabular}{c} 
Acumulada \\
\cline { 2 - 6 }
\end{tabular} \\
\cline { 2 - 7 } & 1,032 & 51,608 & 51,608 & 1,032 & 51,608 & 51,608 \\
\hline
\end{tabular}

Como se constata na Tabela 23, todas as variáveis se correlacionam positivamente (a correlação entre as variáveis e o factor retido é de 0,718). Estes resultados permitem-nos concluir que quanto maior o número de filiais e a facturação para mercados externos, maior a internacionalização. Assim, os scores que resultaram desta análise dão o valor das componentes para cada inquirido, passando a constituir a nova variável independente "internacionalização".

Tabela 23 - Matriz da componente

\begin{tabular}{l|c}
\hline \multirow{2}{*}{} & Componente* \\
\cline { 2 - 2 } & 1 \\
\hline Número de Filiais &, 718 \\
Facturação para Mercados Externos &, 718 \\
\hline * &
\end{tabular}

* Uma componente extraída

No sentido de compararmos o grupo de inquiridos que utilizam e não utilizam e que conhecem e não conhecem o BSC relativamente às novas variáveis independentes (dimensão e internacionalização) efectuamos um teste à normalidade (Tabela 24) para nos indicar se devemos utilizar um teste paramétrico ou um teste não paramétrico para amostras independentes. 
Tabela 24 - Teste à normalidade das variáveis dimensão e internacionalização

\begin{tabular}{|c|c|c|c|c|c|c|c|}
\hline & \multicolumn{3}{|c|}{ Kolmogorov-Smirnov(*) } & \multicolumn{3}{|c|}{ Shapiro-Wilk } \\
\hline & & Estatística & GL & Sig. & Estatística & GL & Sig. \\
\hline \multirow[t]{2}{*}{ Dimensão } & $\begin{array}{l}\text { Utiliza ou já deu os } \\
\text { primeiros passos }\end{array}$ & ,425 & 16 &, 000 & ,479 & 16 & ,000 \\
\hline & Não Utiliza & ,229 & 44 &, 000 & 692 & 44 &, 000 \\
\hline \multirow[t]{2}{*}{ Internacionalização } & $\begin{array}{l}\text { Utiliza ou já deu os } \\
\text { primeiros passos }\end{array}$ & ,447 & 16 &, 000 &, 541 & 16 &, 000 \\
\hline & Não Utiliza & ,374 & 44 &, 000 & ,339 & 44 &, 000 \\
\hline
\end{tabular}

* Correcção de Lilliefors

Os testes de aderência à normalidade, K-S ou Shapiro-Wilk, mostram que para um nível de significância de 5\% a normalidade é violada $(p$-value $<0,05)$, quer para a dimensão, quer para a internacionalização, pelo que para efectuarmos a nossa análise teremos de recorrer ao teste não paramétrico $U$ de Mann-Whitney (Tabela 25).

Tabela 25 - Teste não paramétrico $U$ de Mann-Whitney para a utilização do BSC

\begin{tabular}{l|c|c}
\hline & Dimensão & Internacionalização \\
\hline Mann-Whitney U & 505,000 & 293,000 \\
Z &,- 539 & $-1,248$ \\
Nível Sig. (bilateral) &, 590 &, 212 \\
\hline
\end{tabular}

Os resultados apresentados na Tabela 25 mostram que as duas distribuições não diferem em tendência central, conforme teste $U$ de Mann-Whitney com um nível de significância bilateral de 0,590 para a dimensão e de 0,212 para a internacionalização, ou seja, a diferença entre a utilização e a não utilização do BSC no que respeita à dimensão e à internacionalização não é estatisticamente significativa.

No que se refere ao conhecimento do BSC, o nível de significância bilateral observado (Tabela 26) é de 0,147 para a dimensão e de 0,192 para a internacionalização, aceitando-se a hipótese de que as duas populações são iguais em tendência central, isto é, também a diferença entre os que conhecem e os que não conhecem o BSC, relativamente às variáveis dimensão e internacionalização, não é estatisticamente significativa.

Tabela 26 - Teste não paramétrico $U$ de Mann-Whitney para o conhecimento do BSC

\begin{tabular}{l|c|c}
\hline & Dimensão & Internacionalização \\
\hline Mann-Whitney U & 208,000 & 156,000 \\
Z & $-1,451$ & $-1,303$ \\
Nível Sig. (bilateral) &, 147 &, 192 \\
\hline
\end{tabular}

\section{DISCUSSÃO DOS RESULTADOS E CONCLUSÕES}

Apesar da generalidade dos inquiridos conhecer o BSC, não existe iniciativa e estabelecimento de planos que favoreçam a sua implementação, na medida em que os resultados sugeriram, à semelhança do estudo de Sousa (2001), uma fraca utilização do BSC em Portugal. No que concerne aos motivos justificativos da não adopção ou do abandono, tal como apontado por Speckbacher, Bischof e Pfeiffer (2003), distinguiu-se essencialmente o facto das empresas possuírem outras ferramentas similares e estarem satisfeitas. Constatamos que o processo de implementação é bastante recente (iniciado num grande número de empresas após o ano 2000), o que pode ser um reflexo da visita de Kaplan e Norton a Portugal, e que, contrariamente a Speckbacher, Bischof e Pfeiffer (2003), se registou essencialmente ao nível corporativo.

O facto do processo de implementação não se ter centrado nas UEN "foge" ao defendido por Kaplan e Norton (1996) na consideração de que é ao nível das UEN que a 
estratégia competitiva se torna crucial e, como tal, o BSC deverá ser primeiramente aplicado a essas unidades e posteriormente a toda a organização. No mesmo sentido do referido por Sousa (2001, p. 197), "pode tratar-se de empresas cuja actividade não é muito diversificada, ou (...) do BSC ser muito recente ou ainda nem sequer ter começado a ser implementado. Nesta situação, não é de estranhar que as empresas comecem por desenvolver um BSC a nível da empresa, como forma de estabelecer uma estrutura comum sobre os temas e as visões comuns (...)".

Como causas principais para a adopção do BSC destacaram-se razões relacionadas com a estratégia, nomeadamente com a sua vinculação aos objectivos individuais, com a sua comunicação, execução e desenvolvimento, seguindo-se muito de perto a linha de pensamento de Kaplan e Norton (2001). Ao nível do conteúdo do BSC, confirmou-se a presença das quatro perspectivas básicas recomendadas por Kaplan e Norton (1996), embora, em alguns casos, com denominações diferentes. No entanto, convém salientar um menor peso atribuído à perspectiva de aprendizagem e crescimento [conclusão idêntica à obtida por Sousa (2001)] e o facto de três empresas terem utilizado outras perspectivas, como é o caso da perspectiva de recursos humanos e da perspectiva de infra-estruturas.

Quanto às perspectivas adicionais, e como já tivemos oportunidade de referir, notamos que a perspectiva de recursos humanos aproxima-se da perspectiva de aprendizagem e crescimento e que a perspectiva de infra-estruturas, não é mais do que a perspectiva interna proposta por Kaplan e Norton, pelo que temos muitas dúvidas se realmente se justifica a sua inclusão. Os principais benefícios prendem-se com a melhoria no alinhamento entre objectivos estratégicos e acções, com a clarificação e comunicação da estratégia e com a consistência ao nível dos objectivos.

Os resultados obtidos pela análise bivariada e multivariada realizada permitiram-nos constatar que, embora a nossa amostra esteja concentrada na região de LVT, não existe associação entre a localização geográfica e a utilização do BSC, não se rejeitando a hipótese das variáveis serem independentes, ou seja, a utilização do BSC não difere de forma significativa nas diferentes zonas geográficas. Ao nível do conhecimento do BSC por localização geográfica, os resultados apresentaram-se inconclusivos. Não obstante, registamos um grande conhecimento na região de LVT comparativamente com o resto do país.

Como vimos, este facto pode estar associado à presença de Kaplan e Norton no distrito de Lisboa, bem como à concentração de importantes empresas de consultadoria e de Tecnologias de Informação (TI) nesta zona. Por sua vez, obtivemos evidência empírica da relação entre a utilização do BSC e o sector em que está inserida a empresa, rejeitando-se a hipótese das variáveis estudadas serem independentes, sendo as empresas que pertencem ao sector secundário as que mais aplicam. Esta constatação pode ser um reflexo, como referimos, da competitividade enfrentada por estes sectores no mercado português. Conclusão aliás confirmada pela medida de associação V de Cramer.

Quanto ao conhecimento, qualquer que seja o sector, as empresas demonstram, maioritariamente, conhecer o BSC. Não obstante, de entre aquelas que revelaram não conhecer o BSC, verificamos que são essencialmente empresas pertencentes ao sector terciário. Esta conclusão é algo estranha na medida em que pertencem a este sector empresas de serviços, media, telecomunicações e de TI, ou seja, empresas que enfrentam um mercado altamente competitivo em que se torna fundamental apostar constantemente na inovação e melhoria contínua, quer ao nível dos processos produtivos, quer ao nível dos processos e técnicas de gestão.

Por fim, no âmbito da análise multivariada, obtivemos evidência empírica de que a diferença entre utilizadores e não utilizadores do BSC e entre os que conhecem e desconhecem esta ferramenta no que respeita às variáveis independentes dimensão e internacionalização não é estatisticamente significativa. 


\section{REFERÊNCIAS}

ANDERSEN, Henrik V.; LAWRIE, Gavin; SAVIC, Nenad. Integrating quality management and strategic control through $3^{\text {rd }}$ generation balanced scorecard. In: INTERNATIONAL CONFERENCE ON PERFORMANCE MEASUREMENT AND MANAGEMENT, $4^{\text {th }}$, Edinburgh, 2004. Anais ... Edinburgh, 2004.

BECKER, Brian E.; HUSELID, Mark A.; ULRICH, Dave. El cuadro de mando integral de RRHH: vinculando las personas, la estrategia y los resultados de la empresa. Barcelona: Ediciones Gestión 2000, 2002.

BENCALEIRO, José. Scorecard de capital humano: como medir o activo mais importante da sua empresa. Lisboa: Editora RH, 2007.

BRAAM, Geert; NIJSSEN, Edwin. Exploring determinants of balanced scorecard adoption. In: ANNUAL CONGRESS OF THE EUROPEAN ACCOUNTING ASSOCIATION, $27^{\text {th }}$, Prague, 2004. Anais ... Prague: EAA, 2004.

CHENHALL, R.; LANGFIELD-SMITH, K. Adoption and benefits of management accounting practices: an Australian study. Management Accounting Research, v. 9, n. 1, p.1-19, 1998. doi:10.1006/mare.1997.0060

COOKE, T. Voluntary Corporate disclosure by Swedish companies. Journal of International Financial Management and Accounting, v. 1, n. 2, p.171-195, 1989. doi:10.1111/j.1467-646X.1989.tb00009.x

EXAME. 500 Maiores \& Melhores. Revista Exame, Edição Especial, Setembro, 2004.

FERNANDES, Hermilio. Lean six sigma: estudo do potencial de implantação na Xerox Unidade Industrial Nordeste. 2005. Dissertação (Mestrado em Administração) - Universidade Federal da Bahia, Salvador, 2005.

HOQUE, Zahirul; JAMES, Wendy. Linking balanced scorecard measures to size and market factors: impact on organizational performance. Journal of Management Accounting Research, v. 12, n. 1, p.1-17, 2000. doi:10.2308/jmar.2000.12.1.1

HUSELID, Mark A.; BECKER, Brian E.; BEATTY, Richard W. El cuadro de mando del capital humano: gestión del capital humano par ejecutar la estrategia. Barcelona: Ediciones Deusto, 2005.

JORDAN, Hugues; NEVES, João Carvalho das; RODRIGUES, José Azevedo. O controlo de gestão ao serviço da estratégia e dos gestores. Lisboa: Áreas Editora, 2002.

KAPLAN, Robert; NORTON, David. The strategy focused organization: How balanced scorecard companies thrive in the new business environment. Massachusetts: Harvard Business School, 2001.

KAPLAN, Robert; NORTON, David. Having trouble with your strategy? Then map it. Harvard Business Review, v. 78, n. 5, p.167-176, 2000.

KAPLAN, Robert; NORTON, David. Translating strategy into action: The balanced scorecard. Massachusetts: Harvard Business School, 1996.

KAPLAN, Robert; NORTON, David. El Cuadro de mando integral (The balanced scorecard). Barcelona: Ediciones Gestión 2000, 1997.

KAPLAN, Robert; NORTON, David. The balanced scorecard: measures that drive performance. Harvard Business Review, v. 70, n. 1, p.71-79, 1992. 
KATO, Jerry Miyoshi. Avaliação de desempenho de sistemas logísticos através do seis sigma e balanced scorecard. Revista FAE, v. 6, n. 2, p.113-124, 2003.

OLVE, Nils Göran; ROY, Jan; WETTER, Magnus. Performance drivers: a practical guide to using the balanced scorecard. New York: John Wiley \& Sons, 1999.

PEÑA, José Carlos Nieto. Cómo vincular CRM y estrategia: pasos para implantar el cuadro de mando integral del CRM. Estrategia Financiera, n. 197, p.46-50, 2003.

PEREIRA, Alexandre. Guia prático de utilização do SPSS: análise de dados para ciências sociais e psicologia. Lisboa: Sílabo, 1999.

PESTANA, Maria; GAGEIRO, João. Análise de dados para ciências sociais: a complementaridade do SPSS. Lisboa: Sílabo, 2003.

PINTO, Francisco. Balanced scorecard: alinhar mudança, estratégia e performance nos serviços públicos. Lisboa: Sílabo, 2007.

PYZDEK, Thomas. The six sigma handbook: a complete guide for green belts, black belts and managers at all levels. New York: McGraw-Hill, 2003.

RAMPERSAD, Hubert K. Cuadro de mando integral, personal y corporativo (Total Performance Scorecard, TPS): una revolución en la gestión por resultados. Madrid: MacGraw-Hill/Interamericana, 2004.

SOUSA, Maria. A aplicação do balanced scorecard em Portugal. 2001. Dissertação (Mestrado em Ciências Empresariais) - Universidade do Porto, Porto, 2001.

SPECKBACHER, Gerhard; BISCHOF, Juergen; PFEIFFER, Thomas. A descriptive analysis on the implementation of balanced scorecards in German-Speaking countries. Management Accounting Research, v. 14, n. 4, p.361-387, 2003. doi:10.1016/j.mar.2003.10.001

VERRECCHIA, R. Discretionary disclosure. Journal of Accounting and Economics, v. 5, n. 3, p.179-194, 1983. doi:10.1016/0165-4101(83)90011-3

WATTS, R.; ZIMMERMAN, J. Positive accounting theory: a ten year perspective. The Accounting Review, v. 65, n. 1, p.131-156, 1990. 